УДК 631.527:633.2(470.325)

ГЕНЕТИЧЕСКАЯ КОЛЛЕКЦИЯ МНОГОЛЕТНИХ БОБОВЫХ ТРАВ

БЕЛГОРОДСКОЙ ОБЛАСТИ: ЭТАПЫ ФОРМИРОВАНИЯ, ПУТИ МОБИЛИЗАЦИИ И СЕЛЕКЦИОННЫЙ ПОТЕНЦИАЛ

\author{
Чернявских В.И., Думачева Е.В.
}

ФГАОУ ВО «Белгородский государственный национальный исследовательский университет», Белгород, e-mail: cherniavskih@mail.ru

На базе природно-ландшафтного комплекса «Ботанический сад НИУ БелГУ создана генетическая биоресурсная коллекция многолетних бобовых трав. Целью создания коллекции является изучение полиморфизма проявления отдельных хозяйственно полезных признаков; оценка границ их изменчивости; выделение генетических доноров для использования в селекционной работе с многолетними бобовыми травами, в первую очередь с люцерной изменчивой и клевером посевным. Изучение проводится как на уровне одного растения, так и популяций. Выбран путь создания генетических биоресурсных коллекций бобовых трав ex situ: выращивание растений на определенных полевых участках; сохранение коллекционных образцов в виде генетических банков семян. С использованием исходных форм коллекций ведется адаптивная селекция многолетних бобовых трав на высокую кормовую и семенную продуктивность. Пополнение коллекционного фонда идет за счет сбора местных форм с высокой степенью устойчивости к биотическим и абиотическим стрессам, ценным биохимическим составом, а также привлечением лучших мировых достижений современной селекции. Для полноценного использования и сохранения генетического разнообразия растительных ресурсов региона проведена большая работа по формированию коллекционного фонда хозяйственно ценных родов бобовых трав, разработаны дескрипторы генетических коллекций люцерны изменчивой (более 600 номеров) и клевера ползучего (более 150 номеров). На базе генетической биоресурсной коллекции бобовых трав НИУ БелГУ созданы условия для быстрого поиска необходимого для селекционной работы исходного генетического материала, контроль за поддержанием образцов в живом виде или в виде банка семян. Выделены гендоноры отдельных признаков, с использованием которых получены новые сорта люцерны изменчивой (Краснояружская 1, Краснояружская 2, Алексеевская 1 и Глория) и клевера ползучего (Краснояружский и Илёк).

Ключевые слова: генетическая коллекция, биологические ресурсы, селекция, генетические доноры, люцерна изменчивая, клевер ползучий, новые сорта

\title{
GENETIC COLLECTION OF LONG-TERM BODY GRASSES OF THE BELGOROD REGION: FORMATION STAGES, MOBILIZATION WAYS AND SELECTION POTENTIAL
}

\author{
Chernyavskikh V.I., Dumacheva E.V. \\ Belgorod State National Research University, Belgorod, e-mail: cherniavskih@mail.ru
}

\begin{abstract}
On the basis of the Botanical Garden NRU «BelSU» created a genetic bioresource collection of perennial leguminous herbs. The purpose of the collection is to study the polymorphism of the manifestation of individual economically useful traits; assessment of the boundaries of their variability; selection of genetic donors for use in breeding work with perennial leguminous herbs, primarily with Medicago varia and white clover. The study is conducted at the level of a single plant, and populations. The chosen path is the creation of genetic bioresource collections of legume herbs ex situ: growing plants in certain field sites; saving collection samples in the form of genetic seed banks. Using the original forms of collections, adaptive selection of perennial leguminous grasses for high feed and seed productivity is conducted. The collection fund is replenished by collecting local forms with a high degree of resistance to biotic and abiotic stresses, valuable biochemical composition, as well as attracting the world's best achievements of modern breeding. In order to fully utilize and preserve the genetic diversity of plant resources in the region, a great deal of work has been done to form a collection fund of economically valuable legume species, and descriptors of Medicago varia (more than 600 numbers) and clover (more than 150 numbers) have been developed. On the basis of the genetic bioresource collection of legumes, BelorSU National Research University has created conditions for quickly finding the source of genetic material necessary for the breeding work, monitoring the maintenance of samples in a living form or in the form of a seed bank. Gen donors of individual traits were identified, with the use of which new varieties of alfalfa were obtained (Krasnoyaruzhskaya 1, Krasnoyaruzhskaya 2, Alekseevskaya 1 and Gloria) and red clover (Krasnoyaruzhsky and Ilek).
\end{abstract}

Keywords: genetic collection, biological resources, breeding, genetic donors, Medicago varia, white clover, new varieties

Нехватка природных ресурсов, которая начинает все острее осознаваться человечеством, приводит ученых к пересмотру парадигмы развития и использования растительных генетических ресурсов. В важном деле сохранения генетических ресурсов растений главная роль, по мне- нию ведущих исследователей, принадлежит генетическим коллекциям $[1,2]$. Основателем этого важного направления является академик Н.И. Вавилов, положивший начало крупнейшей коллекции растительных генетических ресурсов Российской Федерации [3]. 
Генетические ресурсы растений представляют собой определенную долю биоресурсов, которые содержат часть наследственного материала и непосредственно или опосредованно важны для селекционного процесса. Они сохраняют уникальное эколого-генетическое и географическое разнообразие представителей различных таксономических групп, являются резерватами признаков адаптации к неблагоприятным условиям внешней среды для селекционеровпрактиков, а также могут быть использованы для организации учебного процесса в системе практико-ориентированного обучения. Важным документом, призванным помочь в организации и сохранении коллекций, является «Положение о российских коллекциях генетических ресурсов культурных растений и их диких родичей (сородичей)» [4].

В мировой практике для идентификации генресурсов применяется ботаническая систематизация; анализ систем размножения; генно-маркерный анализ; идентификация адаптивных стратегий; выявление разнообразных цитогенетических признаков (моносомных и трисомных серий, полиплоидные и анеуплоидные формы), цитоплазматические структуры и др. Для создания генетических биоресурсных коллекций достаточно широко используются методы ex situ:

1) выращивание растений на определенных полевых участках - создание так называемой «живых коллекиий» или «полевых банков», в том числе клоновых посадок различных культур;

2) сохранение коллекционных образцов в виде генетических банков семян $[5,6]$.

Сохранение генофондов коллекций в виде семян в обычных помещениях - способ, хорошо известный и апробированный в течение многих лет ведущими исследовательскими центрами (ВИРом и др.). Обязательным условием при этом является периодический пересев коллекций. Существует как опасность потери семенами всхожести, так и возможность появления точковых мутаций и хромосомных перестроек, даже в период глубокого покоя [6].

При создании генетической коллекции многолетних бобовых трав на базе природно-ландшафтного комплекса «Ботанический сад НИУ БелГУ была поставлена цель: создать коллекционный фонд как основу для изучения биоразнообразия, полиморфизма, оценки границ изменчивости отдельных хозяйственно полезных признаков, выделения генетических доноров для использования в селекционной работе с многолетними бобовыми травами, в первую очередь с люцерной изменчивой и клевером посевным.

\section{Материалы и методы исследования}

На базе кафедры биологии и природно-ландшафтного комплекса «Ботанический сад НИУ БелГУ созданы генетические коллекции бобовых трав - видов, сортообразцов, экотипов и форм, как культурных, так и дикорастущих представителей родов Medicago, Trifolium. Изучение проводится как на уровне одного растения, так и популяций. Коллективом ученых кафедры биологии и природно-ландшафтного комплекса «Ботанический сад НИУ БелГУ был выбран путь создания генетических биоресурсных коллекций бобовых трав $е x$ situ. Исследования ведутся в соответствии с «Методическими указаниями по изучению коллекции многолетних кормовых трав» и другими общепринятыми методиками [7]. Коллекционный фонд служит основой для выделения исходных форм и адаптивной селекции многолетних бобовых трав на высокую кормовую и семенную продуктивность $[8,9]$.

\section{Результаты исследования и их обсуждение}

В мировой флоре к семейству бобовые относится более 12 тыс. видов, из которых около 1850 произрастают на территории России. В культуру же введено лишь 24 вида. Во флористическом списке Белгородской области бобовые входят в первую пятерку по количеству видов. В овражно-балочных комплексах юга Среднерусской возвышенности идентифицированы 16 хозяйственно полезных видов семейства Fabaceae. Было проведено изучение общего габитуса, длительности жизненного цикла бобовых растений, особенности распространения экологических форм и т.д. Установлено, что преобладающими среди хозяйственно полезных видов бобовых являются травянистые стержнекорневые многолетники. Спектр жизненных форм по К. Раункиеру показал, что преобладают среди бобовых гемикриптофиты - 93,75\%. К луговому флороценотипу относится $62,5 \%$, к степному - 25,0\% видов, встречаемых на меловых и каменистых склонах, а также конусах выноса и устьях оврагов. Остальные виды бобовых принадлежат к лесному и синантропному типам [10]. Собранная в НИУ БелГУ коллекция семейства Fabaceae хранится преимущественно $e x$ 
situ в виде генетического банка семян. Пополнение коллекционного фонда ведется по следующим основным направлениям:

- сбор местных форм с высокой степенью устойчивости к биотическим и абиотическим стрессам, ценным биохимическим составом;

- привлечение лучших мировых достижений современной селекции.

Способ сохранения коллекционных образцов в виде семян в условиях обычных помещений широко апробирован на протяжении длительного времени на базе ведущих научных центров (ВИРа, ВИКа и др.). При этом доказана необходимость их периодического пересева, так как даже для бобовых трав, семена которых характеризуются свойством твердосемянности (твердокаменности), есть опасность потери семенами всхожести. Также показано, что в процессе хранения в семенах продолжаются физиолого-генетические перестройки, сопровождающиеся точковыми мутациями и/или хромосомными перестройками. В результате коллекционные образцы претерпевают изменения, а также сохраняется опасность их механического и гибридогенного засорения [6].

Помимо сохранения коллекционного материала бобовых трав в форме ex situ также используется метод «живых коллекций», или «полевых банков». Однако использование этого метода имеет определенный, но важный недостаток - сложно сохранять генетическую чистоту коллекционного материала у перекрестноопыляющихся культур, к каковым относятся бобовые травы. Для поддержания коллекционных образцов создаются изолированные участки, позволяющие сохранять генетическую чистоту семян. Но при этом метод живых коллекций имеет и очень ценное преимущество - позволяет использовать генетическую коллекцию для проведения лабораторных занятий, при выполнении курсовых и бакалаврских работ, магистерских диссертаций студентами кафедры биологии НИУ БелГУ. Особое внимание в Ботаническом саду уделяется изучению видов, сортов и экотипов люцерны. Коллекция этой ценной кормовой культуры, представленная в НИУ «БелГУ», начала формироваться еще в 1970-е гг. усилиями известных отечественных селекционеров: академика PAH А.А. Гончаренко и д.с.-х.н., проф. И.К. Ткаченко. Их работа была продолжена в 1990-2000-х гг. учениками: д.с.-х.н. В.И. Чернявских, д.б.н. Е.В. Думачевой, к.с.-х.н. Т.Н. Глубшевой, к. с.-х. н. Ю.Н. Куркиной, к.с.-х.н. К.Н. Ио- новым и другими. В результате собрана обширная коллекция - более 600 сортов, сортообразцов культурных и дикорастущих форм рода Medicago L. Коллекционные номера отбирались путем мобилизации селекционных образцов и сортов Советского Союза, стран Восточной и Западной Европы, США, привлечением местных сортообразцов и форм из коллекции ВИРа. Важным этапом пополнения коллекций были экспедиционные сборы в 1980-2000-е гг, проведенные на территории Украины, России, Белоруссии, закавказских и среднеазиатских республик. Выделенные в течение многих лет исследований источники ценных биологических и хозяйственных признаков активно используются в настоящее время для работы по различным направлениям селекции люцерны на кормовую ценность, снижение содержания сапонинов, высокую семенную продуктивность, устойчивость к вредителям и болезням, засухоустойчивость, устойчивость к карбонатным почвам.

Для включения образца в коллекцию предварительно изучается его генеалогия, пригодность для конструирования смешанных агроценозов, эдафическая и фитоценотическая комплементарность. Ведется описание каждого образца по ряду количественных признаков: форма розетки осеннего или весеннего отрастания; форма куста; стебли (высота; грубость; опушение; окраска узлов; ветвистость); среднее число междоузлий и амплитуда колебаний; кустистость (сильная, средняя, слабая); облиственность; листья (величина; форма; опушение; окраска; восковой налет; степень мягкости); прилистники (форма; опушение; окраска); соцветие (форма; длина; степень рыхлости; окраска); бобы (величина, форма, окраска, количество завитков); семена (величина; форма; цвет; \% твердых семян); корневая система (мощность развития; выраженность главного корня; наличие клубеньков). В результате многолетних циклов авторами были выделены и изучены формы - источники ценных хозяйственных признаков, обладающие высокой общей комбинационной способностью (ОКС) в питомниках поликросса по продуктивности надземной массы (номера Л 450-455 местные формы с карбонатных обнажений); по семенной продуктивности (Л 235-239индивидуальные отборы из сорта Белгородская 86); высокой облиственностью (Л 347352 - носители $m f$-мутации); устойчивые к аскохитозу (Л-346, Л-492), которые стали гендонорами для новых сортов люцерны из- 
менчивой Краснояружская 1, Краснояружская 2, Алексеевская 1 и Глория. В табл. 1 приведен фрагмент дескриптора коллекции рода Medicago L., который предназначен для информирования селекционеров, биологов, ботаников, работающих с генетическими коллекциями, с целью обмена образцами для использования в фундаментальных, поисковых и прикладных исследованиях.

Таблица 1

Дескриптор генетической и биоресурсной коллекции рода Medicago L. (фрагмент)

\begin{tabular}{|c|c|c|c|c|c|c|c|}
\hline \multirow{2}{*}{$\begin{array}{c}\text { Номер } \\
\text { по каталогу } \\
\text { учреждения }\end{array}$} & \multirow[t]{2}{*}{ Название } & \multirow[t]{2}{*}{\begin{tabular}{c|} 
Видовая \\
принадлежность
\end{tabular}} & \multicolumn{2}{|c|}{ Статус образца } & \multicolumn{2}{|c|}{$\begin{array}{c}\text { Статус } \\
\text { коллекции }\end{array}$} & \multirow{2}{*}{$\begin{array}{c}\text { Селекционно } \\
\text { ценный признак } \\
* * / * *\end{array}$} \\
\hline & & & $*$ & $* *$ & $* / *$ & $* * / *$ & \\
\hline Л-1 & Белгородская 86 & M. varia Mart. & $\mathrm{AC}$ & Россия & $\mathrm{C} / \mathrm{P}$ & ПУ & 2 \\
\hline Л-66 & Europe & M. varia Mart. & $\mathrm{AC}$ & Франция & C,P & БС & 1 \\
\hline Л-67 & Ferax & M. varia Mart. & $\mathrm{AC}$ & США & C,P & БС & 2 \\
\hline Л-68 & Roamer & M. varia Mart. & $\mathrm{AC}$ & Канада & C,P & БС & 1 \\
\hline Л-69 & Sterling & M. varia Mart. & $\mathrm{AC}$ & США & C,P & БC & 1 \\
\hline Л-70 & Suver & M. varia Mart. & $\mathrm{AC}$ & Франция & C,P & БС & 1 \\
\hline Л-71 & Vela & M. varia Mart. & $\mathrm{AC}$ & Дания & $\mathrm{C}, \mathrm{P}$ & БС & 1 \\
\hline Л-72 & Vernal & M. varia Mart. & $\mathrm{AC}$ & США & C,P & БС & 2 \\
\hline Л-73 & Walcabaut & M. varia Mart. & $\mathrm{AC}$ & Австралия & $\mathrm{C}, \mathrm{P}$ & БС & 1 \\
\hline Л-74 & WL-315 & M. varia Mart. & $\mathrm{BR}$ & $\mathrm{M}$ & C,P & БС & 1 \\
\hline Л-89 & Краснояружская 1 & M. varia Mart. & $\mathrm{AC}$ & Россия & $\mathrm{C}, \mathrm{P}$ & ПУ & 1,3 \\
\hline Л-90 & $\begin{array}{l}\text { Отбор из сорта Крас- } \\
\text { нояружская } 1 \mathrm{mf}\end{array}$ & M. varia Mart. & $\mathrm{BR}$ & $\mathrm{M}$ & $\mathrm{C}, \mathrm{P}$ & ПУ & 1,3 \\
\hline Л-93 & Краснояружская 2 & M. varia Mart. & $\mathrm{AC}$ & Россия & $\mathrm{O}, \mathrm{P}$ & ПУ & 2 \\
\hline Л-94 & $\begin{array}{c}\text { Отбор из сорта } \\
\text { Краснояружская } 2\end{array}$ & M. varia Mart. & $\mathrm{BR}$ & $\mathrm{M}$ & $\mathrm{O}, \mathrm{P}$ & ПУ & 2 \\
\hline Л-95 & Алексеевская 1 & M. varia Mart. & $\mathrm{AC}$ & Россия & $\mathrm{O}, \mathrm{P}$ & ПУ & 1,2 \\
\hline Л-96 & $\begin{array}{l}\text { Отбор из сорта } \\
\text { Алексеевская } 1\end{array}$ & M. varia Mart. & $\mathrm{BR}$ & $\mathrm{M}$ & $\mathrm{O}, \mathrm{P}$ & ПУ & 2 \\
\hline Л-97 & Глория & M. varia Mart. & $\mathrm{AC}$ & Россия & $\mathrm{O}, \mathrm{P}$ & ПУ & 1,2 \\
\hline Л-98 & Отбор из сорта Глория & M. varia Mart. & $\mathrm{BR}$ & $\mathrm{M}$ & $\mathrm{O}, \mathrm{P}$ & ПУ & 2 \\
\hline Л-146 & Марусинская 425 & M. varia Mart. & $\mathrm{AC}$ & Россия & $\mathrm{P}$ & БС & 2 \\
\hline Л-147 & Павловская пестрая & M. varia Mart. & $\mathrm{AC}$ & Россия & $\mathrm{P}$ & БС & 1,3 \\
\hline Л-148 & Белгородская 7 & M. varia Mart. & $\mathrm{AC}$ & Россия & $\mathrm{P}$ & ПУ & 1,3 \\
\hline Л-149 & Дарья & M. varia Mart. & $\mathrm{AC}$ & Россия & $\mathrm{P}$ & БС & 3 \\
\hline Л-150 & $\begin{array}{c}\text { Вавиловская } \\
\text { юбилейная }\end{array}$ & M. sativa L. & $\mathrm{AC}$ & Россия & $\mathrm{P}$ & БС & 1 \\
\hline Л-151 & Тамбовчанка & M. sativa L. & $\mathrm{AC}$ & Россия & $\mathrm{P}$ & БС & 1 \\
\hline Л-159 & $\begin{array}{l}\text { Отбор из сорта } \\
\text { Белгородская } 7\end{array}$ & M. varia Mart. & $\mathrm{BR}$ & $\mathrm{M}$ & $\mathrm{P}$ & ПУ & 2 \\
\hline Л-455 & ИО 2/30 mf, 2015 & M. varia Mart. & $\mathrm{BR}$ & $\mathrm{M}$ & $\mathrm{C}, \mathrm{P}$ & ПУ & 1,3 \\
\hline Л-456 & ИО 2/26 mf, 2015 & M. varia Mart. & $\mathrm{BR}$ & $\mathrm{M}$ & $\mathrm{C}, \mathrm{P}$ & ПУ & 1,3 \\
\hline Л-457 & ИО 2/23 mf, 2015 & M. varia Mart. & BR & $\mathrm{M}$ & C,P & ПУ & 1,3 \\
\hline Л-346 & Люцерна желтая & $\begin{array}{c}\text { M. falcata L. } \\
\text { subsp. romanica } \\
\text { (Prodan) Schwarz } \\
\text { et Klinkovski }\end{array}$ & WL & $\mathrm{M}$ & $\mathrm{O}$ & БС & 4 \\
\hline Л-429 & Люцерна желтая & $\begin{array}{c}\text { M. falcata L. } \\
\text { subsp. romanica } \\
\text { (Prodan) Schwarz } \\
\text { et Klinkovski }\end{array}$ & WL & $\mathrm{M}$ & $\mathrm{O}$ & БС & 4 \\
\hline
\end{tabular}

П р и м е ч а н и е. Условные обозначения: * - сорт (AC), дикорастущий вид (WL), селекционный ресурс (BR); ** - местный $(\mathrm{M})$, получен из...; */* - оригинальная $(\mathrm{O})$, сохраняемая $(\mathrm{C})$, рабочая $(\mathrm{P})$; **/* - в полевых условиях (ПУ), генетический банк семян (БС); **/** 1 - высокая продуктивность надземной массы; 2 - высокая семенная продуктивность; 3 - высокая облиственность; 4 - устойчивость к аскохитозу. 
Таблица 2

Дескриптор генетической и биоресурсной коллекции рода Trifolium L. (фрагмент)

\begin{tabular}{|c|c|c|c|c|c|c|}
\hline \multirow{2}{*}{$\begin{array}{c}\text { Номер } \\
\text { по каталогу } \\
\text { учреждения }\end{array}$} & \multirow[t]{2}{*}{ Название } & \multirow[t]{2}{*}{$\begin{array}{c}\text { Видовая } \\
\text { принадлежность }\end{array}$} & \multicolumn{2}{|c|}{ Статус образца } & \multicolumn{2}{|c|}{$\begin{array}{c}\text { Статус } \\
\text { коллекции }\end{array}$} \\
\hline & & & $*$ & ** & $* / *$ & $* * / *$ \\
\hline K-5 & КП-7 & T. alpestre $\mathrm{L}$. & BR & $\mathrm{M}$ & $\mathrm{C}, \mathrm{P}$ & БС \\
\hline K-23 & ДП-33 & T. arvense $\mathrm{L}$. & $\mathrm{BR}$ & $\mathrm{M}$ & $\mathrm{C}, \mathrm{P}$ & БС \\
\hline K-24 & ДП-34 & T. arvense $\mathrm{L}$. & BR & $\mathrm{M}$ & $\mathrm{C}, \mathrm{P}$ & БС \\
\hline K-40 & ДП-2 & T. fragiferum $\mathrm{L}$. & BR & $\mathrm{M}$ & $\mathrm{C}, \mathrm{P}$ & БС \\
\hline K-66 & Краснояружский & T. repens L. & $\mathrm{AC}$ & Россия & $\mathrm{C}, \mathrm{P}$ & ПУ \\
\hline К-67 & $\begin{array}{l}\text { Отбор из сорта } \\
\text { Краснояружский }\end{array}$ & T. repens $\mathrm{L}$. & BR & $\mathrm{M}$ & $\mathrm{C}, \mathrm{P}$ & ПУ \\
\hline К-68 & Казацкий & T. pratense $\mathrm{L}$. & $\mathrm{AC}$ & Россия & $\mathrm{C}, \mathrm{P}$ & ПУ \\
\hline K-69 & Отбор из сорта Казацкий & T. pratense $\mathrm{L}$. & BR & $\mathrm{M}$ & $\mathrm{O}, \mathrm{P}$ & БC \\
\hline K-70 & Орловский среднеранний & T. pratense $\mathrm{L}$. & $\mathrm{AC}$ & Россия & $\mathrm{O}, \mathrm{P}$ & БС \\
\hline
\end{tabular}

Аналогичная работа в настоящее время ведется с видами, сортами и сортообразцами рода Trifolium L., коллекция которых насчитывает более 150 номеров. В табл. 2 приведен перечень номеров коллекции, оличающихся высокой декоративностью, что является важным для формирования сортов газонного типа.

С использованием доноров ценных селекционных признаков создан и включен в Государственный реестр селекционных достижений сорт клевера ползучего Краснояружский, передан в 2018 г. в Госсортоиспытание новый сорт клевера ползучего Илёк. Идет работа по сбору генетического материала и закладке генетических и биоресурсных коллекций других хозяйственно ценных родов семейства Fabaceae. На очереди - создание генетических коллекций, хранящих генофонды лекарственных и ароматических растений, включая виды фармакологические, необходимые для селекции на фитонцидные, гомеопатические, адаптогенные, антиоксидантные и антимикробные свойства.

\section{Выводы}

1. Для полноценного использования и сохранения генетического разнообразия растительных ресурсов региона проведена большая работа по формированию коллекционного фонда хозяйственно ценных родов бобовых трав, разработаны дескрипторы генетических коллекций люцерны изменчивой и клевера ползучего.

2. На базе генетической биоресурсной коллекции бобовых трав НИУ БелГУ созданы условия для быстрого поиска необходимого для селекционной работы исходного генетического материала, контроль за поддержанием образцов в живом виде или в виде банка семян.

3. Выделены доноры ценных хозяйственных признаков (высокой семенной продуктивности и продуктивности надземной массы; облиственности; устойчивости к аскохитозу), которые стали исходным материалом для новых сортов люцерны изменчивой Краснояружская 1 , Краснояружская 2, Алексеевская 1 и Глория, а также клевера ползучего (Краснояружский и Илёк).

Исследование выполнено при поддержке гранта на проведение НИР по приоритетным направлениям развития агропромыиленного комплекса Белгородской области (Соглашение № 2 от 12 ноября 2018 г.) на тему: «Формирование селекиионно-семеноводческой базы медоносных культур в условиях мальх форм хозяйствования».

\section{Список литературы / References}

1. Дзюбенко Н.И. Генетические ресурсы культурных растений - основа продовольственной и экологической безопасности России // Вестник РАН. 2015. Т. 85. № 1. С. 3-8. DOI: $10.7868 / \mathrm{S} 0869587315010041$.

Dzyubenko N.I. Genetic resources of cultivated plants - the basis of food and environmental security of Russia // Herald of the Russian Academy of Sciences. 2015. V. 85. № 1. P. 15-19. DOI: $10.1134 / \mathrm{S} 1019331615010013$.

2. Савченко И.В. Выведение новых сортов и гибридов сельскохозяйственных растений // Вестник РАН. 2017. Т. 87. № 4. C. 325-332. DOI: 10.7868/S0869587317040065.

Savchenko I.V. Breeding new varieties and hybrids of agricultural plants // Vestnik RAN. 2017. V. 87. № 4. P. 325-332 (in Russian).

3. Vavilov N.I. Origin and geography of cultivated plants. Cambridge: Cambridge Univ. Press, 1992. 498 p.

4. Положение о российских коллекциях генетических ресурсов культурных растений и их диких родичей (сородичей). М.: Россельхозакадемия, 2010. С. 1-13.

Regulations on Russian collections of genetic resources of cultivated plants and their wild relatives (relatives). M .: Russian Agricultural Academy, 2010. P. 1-13 (in Russian). 
5. Беспалова Л.А. Развитие генофонда как главный фактор третьей зелёной революции в селекции пшеницы // Вестник РАН. 2015. Т. 85. № 1. C. 9-11. DOI: 10.7868/ S086958731501003X.

Bespalova L.A. Gene pool development as the main factor of the third green revolution in wheat breeding // Vestnik RAN. 2015. № 1. P. 9-11 (in Russian).

6. Железнов А.В., Железнова Н.В., Бурмакина Н.В., Леонова Н.С., Юдина Р.С. Создание, сохранение, изучение и использование генофонда кормовых и лекарственных растений в ИЦИГ СО РАН // Информационный вестник ВОГиС. 2008. Т. 12. № 4. С. 580-589.

Zheleznov A.V., Zheleznova N.V., Burmakina N.V., Leonova N.S., Yudina R.S. Generation, preservation, study and use of the gene pool of forage and medicinal plants in the ICIG SB RAS // Informacionnyj vestnik VOGiS. 2008. V. 12. № 4. P. 580-589 (in Russian).

7. Лубенец П.А., Иванов А.И., Кириллов Ю.И. Методические указания по изучению коллекции многолетних кормовых трав. Ленинград: ВИР, 1975. 37 с.
Lubenets P.A., Ivanov A.I., Kirillov Y.I. Guidelines for the study of the collection of perennial forage grasses. Leningrad: VIR, 1975. 37 p. (in Russian)

8. Lisetskii F.N., Chernyavskikh V.I., Degtyar O.V. Pastures in the Zone of Temperate Climate: Trends for Development, Dynamics, Ecological Fundamentals of Rational Use. Pastures: Dynamics, Economics and Management, 2010. P. 51-84.

9. Dumacheva E.V., Cherniavskih V.I., Gorbacheva A.A., Vorobyova O.V., Borodaeva Z.A., Bespalova E.N., Ermakova L.R. Biological resources of the Fabaceae family in the Cretaceous south of Russia as a source of starting material for drought-resistance selection. International Journal of Green Pharmacy. 2018. V. 12. № 2. P. 354-358.

10. Dumacheva E.V., Cheriavskih V.I. Particular Qualities Of Micro Evolutionary Adaptation Processes In Cenopopulations Medicago L. On Carbonate Forest-Steppe Soils In European Russia. Middle East Journal of Scientific Research. 2013. V. 17. № 10. P. 1438-1442. 